\title{
When self-interest is key to a better environment
}

As economists and ecologists seek to build intellectual bridges between their disciplines, economic incentives are already being used to protect the natural environment and the 'services' it provides to society. These incentives take many forms, from the tourist dollar to tradable pollution permits. All are becoming more effective as natural amenities become scarce - and therefore more highly prized.

Perhaps the most straightforward example of 'doing well by doing good' is 'ecotourism'. For example, the South African company ConsCorp (Conservation Corporation) has agreed with local landowners to restore several hundred thousand hectares of farmland to their original state and to stock the land with animals. Land that yielded $\$ 25$ to $\$ 70$ per hectare a year for ranching or farming now yields $\$ 200$ to $\$ 300$. Visitors pay a premium to see (and hunt) lions and leopards, so there is a great incentive to maintain the ecosystem needed to support these pinnacles of the food chain.

\section{Clean water cheaply}

Conservation can also lead to the avoidance of costs that would otherwise be incurred. For example, protecting watersheds from development is a relatively cheap way to provide clean, abundant water for downstream users.

New York City avoided paying more than $\$ 6$ billion for a water filtration plant (plus running costs of about $\$ 300$ million a year) by investing $\$ 1-\$ 1.5$ billion in restoring the soil ecosystems of the Catskill mountains watershed (see Nature 391, 629-630; 1998). By buying land in the Catskills and restricting its use, the city government was able to preserve the water filtration capabilities of the watershed, instead of replacing this 'service' with a more expensive, engineered solution.

Extended globally, there could be an economic justification for conserving up to 13 per cent of the world's land area for its watershed value to urban water supplies, according to Walter Reid, a visiting fellow at the World Resources Institute in Washington DC.

In these examples, an economic incentive exists for preserving an ecosystem because it supports goods or services with a clear market value. These goods and services have the property of 'excludability' — it is possible to exclude people from consuming them, and so make people pay for such consumption.

Most of the services provided to humans by ecosystems, however, have a non-excludable character; that is, they provide benefits to people who may never set foot in the ecosystem, or even be aware of its existence. Such

services include the retention of soil and prevention of flooding by vegetated landscapes, and the role of birds and insects in pest control and pollination. In the most extreme example of a shared benefit, the sequestration of carbon by a hectare of forest benefits all humans by offsetting greenhouse-gas emissions. The owner of land supplying such services does not receive any compensation for them, and so has no economic incentive to conserve the resource.

The economist's solution to the problem of non-excludability takes the form of assigning an appropriate kind of property rights, in the same way that patents and copyrights protect knowledge. In the environmental realm, examples include grazing rights, fishing quotas and water rights.

For maximum economic efficiency, these rights should be 'tradable', giving them a market value and creating incentives for conservation. The US government has addressed many of its air pollution problems by means of emissions permits. One notable success has been the programme of tradable sulphur dioxide emissions allowances set up by the

\section{Progress and pitfalls along the path towards}

One goal that unites most ecological economists is the desire to develop a system of national accounting that embraces environmental factors excluded from current definitions of gross domestic product (GDP).

The conventional assessment of GDP, which is around 50 years old, works by adding up all the final demands for goods and services produced annually by a nation. Although widely used by economists, journalists and politicians as the measure of the economic health of a country, GDP has been much criticized by environmentalist groups - backed by some sympathetic economists - on the grounds that it paints a potentially misleading picture of a society's health when seen in environmental terms.

"A country could exhaust its mineral resources, cut down its forests, erode its soils, pollute its aquifers, and hunt its wildlife and fisheries to extinction, but its GDP would not be affected as these assets disappeared," says Robert Repetto, an environmental and resource economist at the World Resources Institute, an independent research organization in Washington DC.

Repetto has pioneered work on a greener GDP. His study in Indonesia in 1989 concluded that annual GDP growth
Clean Air Act amendments of 1990. In this programme, the targeted emissions reductions have been exceeded, saving $\$ 1$ billion a year compared with non-market-based 'command and control' policy alternatives.

Largely as a result of pressure from the United States, the Kyoto Protocol on climate change goes further, providing not just for tradable carbon dioxide emission permits, but for permits to be given to countries that contrive to sequester an equivalent amount of carbon - for example, by reforestation.

This could profoundly affect the economics of forest conservation, especially as the protocol's Clean Development Mechanism would allow developed countries to pay for forest conservation in developing countries. Geoffrey Heal, of Columbia University's Graduate School of Business, estimates that growing forests might earn carbon sequestration credits at a rate of $\$ 70$ to $\$ 800$ per hectare per year. This compares favourably with maximum annual profits from ranching in Costa Rica of $\$ 100$ to $\$ 125$ per hectare.

Not everyone is enthusiastic about tradable emissions permits, which some environmentalists characterize as "licences to pollute". Robert Costanza of the University of Maryland prefers pollution taxes, on the grounds that these give polluters an incentive to reduce emissions "all the way down to corrected for depreciation in timber, petroleum and soil resources was 3 per cent lower than the conventionally calculated figure of 7.1 per cent between 1971 and 1984.

More radical ecological economists such as Herman Daly (see page 427) take a different view. They criticize the idea that a country's wealth can be measured just in terms of how much its citizens produce.

Daly has helped to develop what he and colleagues refer to as the Index of Sustainable Economic Welfare (ISEW). Although this takes GDP as its starting

\begin{tabular}{|c|c|c|c|}
\hline \multicolumn{4}{|c|}{ How green is your country? } \\
\hline \multirow[t]{2}{*}{ Country } & \multirow[t]{2}{*}{ GNP } & \multicolumn{2}{|c|}{ Green NNP } \\
\hline & & $\begin{array}{r}\text { (\$ per capita } \\
1993)\end{array}$ & $\begin{array}{l}\% \text { fall } \\
\text { on } \\
\text { GNP }\end{array}$ \\
\hline Japan & 31,449 & 27,374 & -13.0 \\
\hline Norway & 25,947 & 21,045 & -18.9 \\
\hline United States & 24,716 & 21,865 & -11.5 \\
\hline Germany & 23,494 & 20,844 & -11.3 \\
\hline South Korea & 7,681 & 7,041 & -8.3 \\
\hline South Africa & 3,582 & 2,997 & -16.3 \\
\hline Brazil & 2,936 & 2,579 & -12.2 \\
\hline Indonesia & 732 & 616 & -15.8 \\
\hline China & 490 & 411 & -16.1 \\
\hline India & 293 & 242 & -17.4 \\
\hline
\end{tabular}

Green Net National Product (NNP) is Gross National Product (GNP) minus depreciation of produced assets, depletion of forests and subsoil assets, and damage from carbon dioxide emissions. 
zero". But others say a tax encourages polluters to reduce emissions only to the point where the cost of further abatement exceeds the cost of the tax. So the choice between tradable permits and taxes rests on politics and philosophy, rather than economics.

\section{Market-based conservation}

Admittedly, many ecosystem services are not yet scarce enough to lend themselves to a market-based conservation mechanism. In other cases, appropriate institutions (or regulations) do not yet exist to assign and enforce the relevant property rights.

But, at least in the United States, where the climate for markets is particularly favourable, there is a wealth of activity in 'enviro-capitalism'. For example, in a trade brokered by the Washington-based Environmental Defense Fund (EDF) in 1993, a large farm in Oregon agreed to lease its rights to divert tens of millions of cubic metres of water from the Snake River to the Bonneville Power Administration (BPA), a federal agency that markets hydropower generated by government-owned dams. The BPA was required by the Endangered Species Act to increase flows at certain times of year to improve conditions for threatened salmon populations. After a three-year pilot project, the trade was made permanent in April 1997, when the Department of the Interior

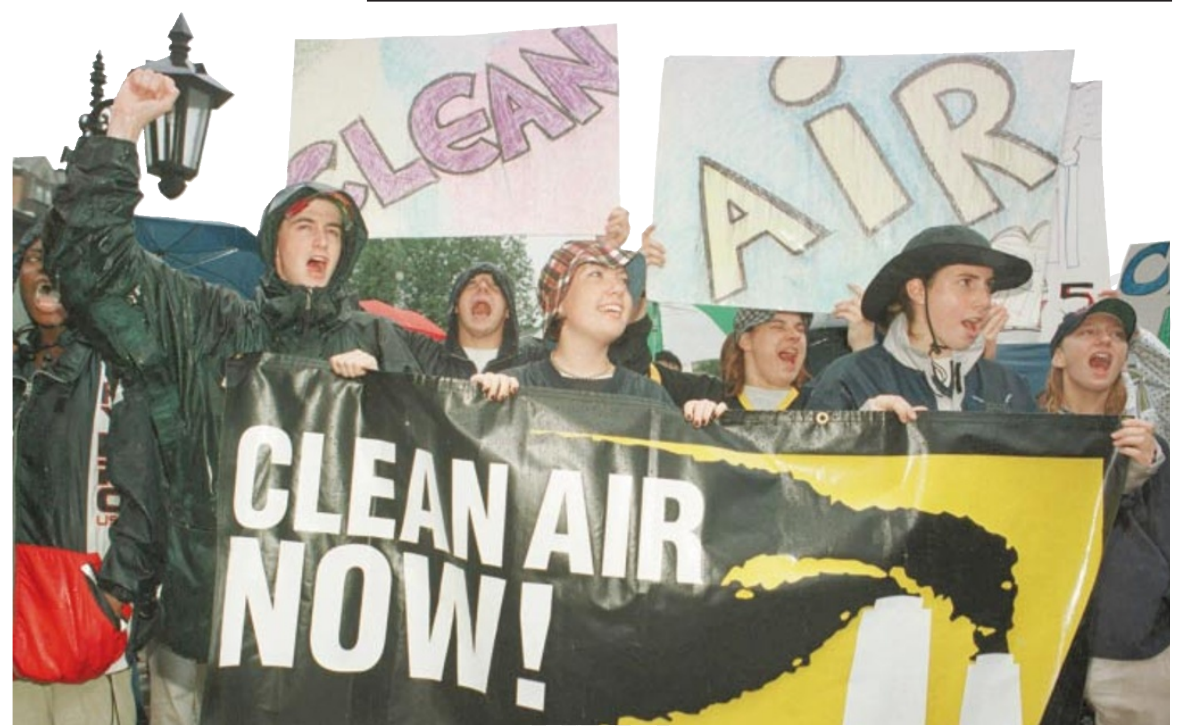

Pressure point: tradable emissions permits offer one answer to public demands for clean air.

acquired the water rights.

Now the Environmental Resources Trust, a sister organization of the EDF, is marketing the electricity generated by these and other "fish flows" on the Snake and Columbia Rivers as "clean power".

Another straw in the wind comes from elsewhere in the US energy industry. The Electric Power Research Institute (EPRI), a research consortium for the energy industry, is helping one of its member companies,
Allegheny Power, to incorporate the principles of ecological resource management into a land management plan.

Another EPRI member, Southern California Edison, has decided to go into the "conservation banking" business: by agreeing not to develop an ecologically significant site, it earns the right to sell development credits to other parties. So in this industry, at least, economic incentives for conservation are starting to have an effect.

\section{a 'greener' method of calculating national productivity}

point, it adds the value of unpaid household work, and then subtracts the cost of pollution, as well as urbanization, road accidents and advertising. But, for all its intellectual attractions, the ISEW has had little success among policymakers. It has also been criticized by more mainstream economists, mainly because of questions about the accuracy of measuring some of its components.

Despite such shortcomings, since the beginning of the decade, calls for a green GDP have been getting louder. In 1993, in response to such suggestions, the United Nations (UN) Statistical Division in New York, which is responsible for setting guidelines for national accounting systems, carried out a review of possible alternatives.

But the review concluded that there was a lack of sufficient data to be able to recommend that countries adopt a green index, or, indeed, a new welfare index.

Instead, countries were encouraged merely to publish separate indicators on the state of key environmental services, as well as their associated monetary values, in parallel with conventional measurements of GDP.

In response to such suggestions, the European Commission is already working on 60 environmental 'pressure indices' intended to act as a measure of the health of various natural resources.

In parallel, the commission is working with the $\mathrm{UN}$ and the Organization for Economic Cooperation and Development (OECD) on so-called 'satellite accounts' that attempt to put monetary values on different aspects of environmental degradation.

The US Environmental Protection Agency has also started a project that seeks to quantify certain ecological services, although this has run into problems in Congress.

There are several other reasons why a green GDP has not been taken up. One is the lack of agreement on its components and on how the index would be calculated.

A second reason is that GDP was never intended to be used as an indicator of environmental health, or indeed of prosperity. And some policymakers see little point in trying to turn it into something that was not originally intended.

Third, there has been unexpected enthusiasm among governments for the Human Development Index (HDI), a qualityof-life indicator that is based on average life expectancy at birth, literacy level, number of years at school and GDP per capita.

Another equally important reason for scepticism about a new green index is the lack of detailed knowledge of its potential components, such as an accurate measure of water pollution, or the climate change potential of greenhouse gases. The UN review team felt that the work on parallel indicators - which many countries are now carrying out - would help to address most of these issues.

"There was a feeling at the time that if we want to include environmental resources in GDP, we must have comprehensive information," says Kirk Hamilton, a senior economist at the environment department of the World Bank. "That means having detailed knowledge of each type of damage by each pollutant."

Many of these gaps are now being filled. But Hamilton points out that most rich countries remain unconvinced about the desirability of a new index, partly because they derive a smaller share of their earnings from natural resources than developing countries, but also because the parallel indicators are, in themselves, an adequate guide to environmental health.

Despite the setbacks, environmental and ecological economists continue to argue the case for a single index that integrates a measure of the wealth of a country's citizens and the health of its natural environment. Progress towards this goal has been slow. But few have given up hope that it can be achieved in a generally acceptable way. 